\section{IGCS20 1311}

\section{INFLAMMATORY MARKERS IN GYNECOLOGIC ONCOLOGY PATIENTS HOSPITALIZED WITH COVID-19}

${ }^{1} \mathrm{M}$ Smith*, ${ }^{1} \mathrm{O}$ Lara, ${ }^{2} \mathrm{R}$ O'Cearbhaill, ${ }^{3} \mathrm{M}$ Sutter, ${ }^{4} \mathrm{~A}$ Knisely, ${ }^{5} \mathrm{~J}$ McEachron, ${ }^{6} \mathrm{~L}$ Gabor, ${ }^{7} \mathrm{C}$ Carr, ${ }^{7} \mathrm{~S}$ Blank, ${ }^{7} \mathrm{M}$ Prasad-Hayes, ${ }^{8} \mathrm{M}$ Frey, ${ }^{2} \mathrm{~J}$ Jee, ${ }^{1} \mathrm{~J}$ Fehniger, ${ }^{5} \mathrm{YC}$ Lee, ${ }^{4} \mathrm{~S}$ Isani, ${ }^{4} J$ Wright, 'B Pothuri. 'Department of Obstetrics and Gynecology, NYU Langone Health, USA; ${ }^{2}$ Department of Medical Oncology, Memorial Sloan Kettering Cancer Center, USA; ${ }^{3}$ Department of Population Health, NYU Langone Health, USA; ${ }^{4}$ Department of Obstetrics and Gynecology, College of Physicians and Surgeons, Columbia University, USA; ${ }^{5}$ Department of Obstetrics and Gynecology, State University of New York Downstate Medical Center, USA; ${ }^{6}$ Department of Obstetrics and Gynecology and Women's Health, Montefiore Medical Center and Albert Einstein College of Medicine, USA; ${ }^{7}$ Department of Obstetrics and Gynecology, Mount Sinai Hospital System, USA; ${ }^{8}$ Department of Obstetrics and Gynecology, Weill Cornell Medicine, USA

\subsection{6/ijgc-2020-IGCS.253}

Introduction Elevated inflammatory markers in COVID-19 infection are predictive of disease severity and mortality. It is unclear if these markers are associated with severe disease in patients with cancer due to underlying tumor related inflammation. We sought to further understand the inflammatory response related to COVID-19 in gynecologic cancer patients.

Methods Patients with history of gynecologic cancer hospitalized for COVID-19 infection with available laboratory data were identified. Laboratory values at the time of hospital admission and clinical outcomes were abstracted from electronic medical records. Severe infection was defined as infection requiring ICU admission or resulting in death.

Results 86 patients with gynecologic cancer were hospitalized with COVID-19 infection with median age of 68.5 years (interquartile range (IQR), 59.0 to 74.8 years). Of the 86 patients, 29 (33.7\%) patients required ICU admission and 25 (29.1\%) patients died of COVID-19 complications. There were $36(41.9 \%)$ patients in remission and 50 (58.1\%) had active disease. Patients with severe infection had significantly higher ferritin (median 1163.0, IQR 640.0-1967.0) and Creactive protein (CRP) (median 142.0, IQR 62.5-217.1) levels than those with non-severe disease (median 624.0, IQR
269.7-954.0, $\mathrm{P}=0.01$; median 62.3, IQR 13.0-159.1, $\mathrm{P}=0.02$ respectively) (table 1). White blood cell count, absolute neutrophil count, and lactate were also associated with severe disease. Procalcitonin and D-Dimer levels were not significantly associated with severe disease $(\mathrm{P}=0.2 ; \mathrm{P}=0.7$ respectively).

Conclusion/Implications Inflammatory markers (ferritin and CRP) in gynecologic cancer patients are associated with COVID-19 severity and can be used as prognostic markers at the time of admission.

\section{IGCS20_1312}

\section{THE IMPORTANCE OF BIOMARKER EXPRESSION IN ADDITION TO LYMPH NODE STATUS IN THE ESMO RISK STRATIFICATION OF ENDOMETRIAL CANCER}

${ }^{1} S$ Vrede*, 'W Van Weelden, ${ }^{2} \mathrm{~N}$ Visser, ${ }^{1} \mathrm{~L}$ van der Putten, ${ }^{1} \mathrm{~J}$ Bulten, ${ }^{3} \mathrm{~K}$ van de Vijver, ${ }^{4} \mathrm{~A}$ van der Wurff, ${ }^{5} \mathrm{M}$ Snijders, ${ }^{6} \mathrm{H}$ Vandevelde, ${ }^{1} \mathrm{C}$ Reijnen, ${ }^{1} \mathrm{~J}$ Pijnenborg. ${ }^{1}$ Department Obstetrics and Gynaecology, Radboudumc, Netherlands; 'Department of Pathology, Stichting PAMM, Netherlands; ${ }^{3}$ Department of Pathology, Radboudumc, Netherlands; ${ }^{4}$ Department of Pathology, Ghent Unisversity Hospital, Belgium; ${ }^{5}$ Department Obstetrics and Gynaecology, CWZ, Netherlands; ${ }^{6}$ Department of Pathology, Elisabeth-Tweesteden Hospital, Netherlands

\subsection{6/ijgc-2020-IGCS.254}

Objectives Investigate the importance of a set of easy accessible biomarkers besides lymphnode(LN) status within the ESMO risk stratification for optimizing adjuvant treatment in endometrial cancer.

Methods Within the European Network for Individualized Treatment of Endometrial Cancer (ENITEC), a retrospective multicenter cohort study was performed with a median follow-up of 5.5-years. Immunohistochemical analysis of tumor protein 53(p53), estrogen receptor(ER), progesterone receptor (PR) and L1 cell-adhesion molecule(L1CAM) expression were analyzed on pre-operative specimens. Biomarker expression was related to $\mathrm{LN}$ status, defined as positive(N1), negative (N0) or unknown $(\mathrm{Nx})$. Correlations and Cox regression analysis were performed.

Abstract 294 Table 1 Laboratory data at hospital admission in patients with severe vs. non-severe COVID-19 infection

\begin{tabular}{lllll}
\hline Laboratory Data- median (IQR) & All patients $(\mathrm{N}=86)$ & Non-Severe $(\mathrm{N}=57)$ & Severe $(\mathrm{N}=29)$ & P-value \\
\hline White blood cell count- per $\mathrm{mm}^{3}$ & $6.9(4.4-12.1)$ & $6.6(4.2-10.1)$ & $11.0(5.9-15.8)$ & 0.03 \\
Absolute neutrophil count- per $\mathrm{mm}^{3}$ & $5.4(3.2-9.9)$ & $5.1(3.0-7.9)$ & $8.8(3.7-13.9)$ & 0.04 \\
Lymphocyte count- per $\mathrm{mm}^{3}$ & $0.8(0.6-1.1)$ & $0.9(0.6-1.2)$ & $0.8(0.5-1.1)$ & 0.23 \\
Hemoglobin- $\mathrm{g} / \mathrm{dL}$ & $10.8(9.0-12.8)$ & $11.2(8.7-12.9)$ & $10.6(9.2-11.7)$ & 0.23 \\
Platelets- per mm $\mathrm{mm}^{3}$ & $236.0(173.0-347.0)$ & $241.0(174.0-319.0)$ & $231.0(168.2-347.8)$ & 0.82 \\
Aspartate aminotransferase- $\mathrm{U} / \mathrm{L}$ & $37.0(25.0-56.5)$ & $34.0(24.5-55.0)$ & $44.0(28.5-83.5)$ & 0.06 \\
Alanine aminotransferase- $\mathrm{U} / \mathrm{L}$ & $26.0(16.2-43.2)$ & $25.0(17.0-38.0)$ & $28.0(15.0-56.0)$ & 0.53 \\
Lactate- mmol/L & $1.4(1.0-2.6)$ & $1.1(0.9-1.8)$ & $2.2(1.4-5.3)$ & 0.005 \\
Lactate dehydrogenase- $\mathrm{U} / \mathrm{L}$ & $371.0(310.8-470.2)$ & $347.0(308.0-453.8)$ & $412.0(336.0-600.2)$ & 0.09 \\
Serum creatinine- mg/dl & $1.0(0.7-1.8)$ & $0.8(0.7-1.2)$ & $1.7(0.9-2.5)$ & 0.09 \\
Troponin- $\mathrm{ng} / \mathrm{mL}$ & $0.03(0.01-0.1)$ & $0.02(0.01-0.08)$ & $0.03(0.02-0.1)$ & 0.24 \\
Total bilirubin- $\mathrm{mg} / \mathrm{dL}$ & $0.5(0.3-0.7)$ & $0.4(0.3-0.7)$ & $0.5(0.4-0.8)$ & 0.7 \\
Ferritin- $\mathrm{ug} / \mathrm{mL}$ & $673.0(320.0-1627.0)$ & $624.0(269.7-954.0)$ & $1163.0(640.0-1967.0)$ & 0.01 \\
D-Dimer- ug/L & $5.6(1.3-423.5)$ & $3.0(1.0-400.0)$ & $10.7(3.1-424.5)$ & 0.7 \\
Procalcitonin- $\mathrm{ng} / \mathrm{mL}$ & $0.2(0.1-0.7)$ & $0.2(0.1-0.3)$ & $0.8(0.2-5.1)$ & 0.2 \\
C-reactive protein- $\mathrm{mg} / \mathrm{L}$ & $83.0(13.9-189.0)$ & $62.3(13.0-159.1)$ & $142.0(62.4-217.1)$ & 0.02 \\
\hline
\end{tabular}

